\title{
Calculation of stress intensity factors for an interfacial notch of a bi-material joint using photoelasticity
}

\author{
M. M. Mirsayar*
}

Zachry Department of Civil Engineering, Texas A\&M University, College Station, TX 77843-3136, USA

\begin{tabular}{l}
\hline A R T I C L E I N F O \\
\hline Article history: \\
Received March 20, 2013 \\
Received in Revised form \\
September, 14, 2013 \\
Accepted 22 September 2013 \\
Available online \\
23 September 2013 \\
\hline Keywords: \\
Photoelasticity \\
Stress intensity factors \\
Bi-material joint \\
Bi-material notch \\
Brazilian disc specimen
\end{tabular}

\section{A B S T R A C T}

In this paper, the stress intensity factors (SIFs) for an interfacial notch in a bi-material joint have been calculated using the experimental method of photoelasticity. A bi-material Brazilian disc specimen with a central interface notch was employed to determine the SIFs for different mode mixities. In this approach, SIFs were calculated experimentally for an Al/Polycarbonate bi-material Brazilian disc specimen and two different loading angles (i.e. modes I and II dominated loading conditions). The results of experimental approach were then compared with the numerical values of finite element method. Experimental results were in good consistency with the numerical values.

(C) 2013 Growing Science Ltd. All rights reserved.

\section{Introduction}

Bi-material joints are increasingly used for various engineering applications. A stress singularity may develop at an interface corner when the bonded materials are subjected to mechanical and/or thermal loading. Since failure is most likely to be initiated from a singular point, it is therefore important to properly characterize the singular stresses around the interface notches. The stress intensity factors characterize the singular stress field close to the notch tip. Hence, calculating the SIFs is the first step for investigating fracture behaviour of interface notched specimens. Although there are some experimental investigations for stress analysis of interface cracks (Ravichandran \& Ramesh, 2004, 2005), the experimental evaluation of stress field for a bi-material and simple notches has rarely been investigated (Ayatollahi et al., 2011, 2013). Mirsayar and Samaei (2013) recently have investigated the effects of combination of materials on the shape and size of the Photoelastic fringe patterns near the interface notch tip. In this research, the stress intensity factors of an interface notch were

* Corresponding author.

E-mail addresses: mirmilad@neo.tamu.edu (M. M. Mirsayar) 
determined by the technique of photoelasticity. The Brazilian disc specimen subjected to diametral compression is one the favorite test samples for investigating the tensile strength and fracture behaviore of cracks and notches in different engineering materials (Chang et al., 2002; Ayatollahi \& Aliha, 2008, Aliha \& Ayatollahi, 2009; Torabi \& Taherkhani, 2011; Torabi \& Jafarinezhad, 2012; Aliha et al., 2012; Aliha, 2013). In this paper, by employing the Brazilian disc specimen containing a bi-material notch, the SIFs in predominant mode I and mode II conditions were determined. Using this specimen, different mode mixities could be easily simulated by changing the loading angle. Moreover, the variations of SIFs against the loading angle were evaluated numerically.

\section{Asymptotic stress field near the interface corner of a bi-material joint}

One can express the asymptotic free-edge stress field near an interface corner of a joint subjected to a remote mechanical load, and having a local edge geometry shown in Fig. 1 as (Ayatollahi et al., 2010)

$$
\sigma_{\mathrm{ij}}^{\mathrm{m}}=\sum_{k=1}^{N} H_{k} r^{\lambda_{k}-1} f_{i j k}^{m},
$$

where $(i, j) \equiv(r, \theta)$ are plane polar coordinates centered at the interface corner. $m(=1,2)$ is the material number and $\lambda_{k}(k=1, N)$ are the eigenvalues of the problem which are determined by solving characteristic equation given in Ayatollahi et al. (2010). $f_{i j k}$ are non-dimensional functions of the eigenvalue $\lambda_{k}$, the local edge geometry characterized by angles $\theta_{1}$ and $\theta_{2}$, and the polar coordinate component of $\theta$ (Ayatollahi et al., 2010). $H_{k}$ is also the wedge corner stress intensity associated with the eigenvalue $\lambda_{k}$. The stress intensities corresponding to $\mathrm{k}=1,2$ (coefficients $H_{k} \mathrm{k}=1,2$ ) are related to mode I and mode II SIFs of the singular stress field.

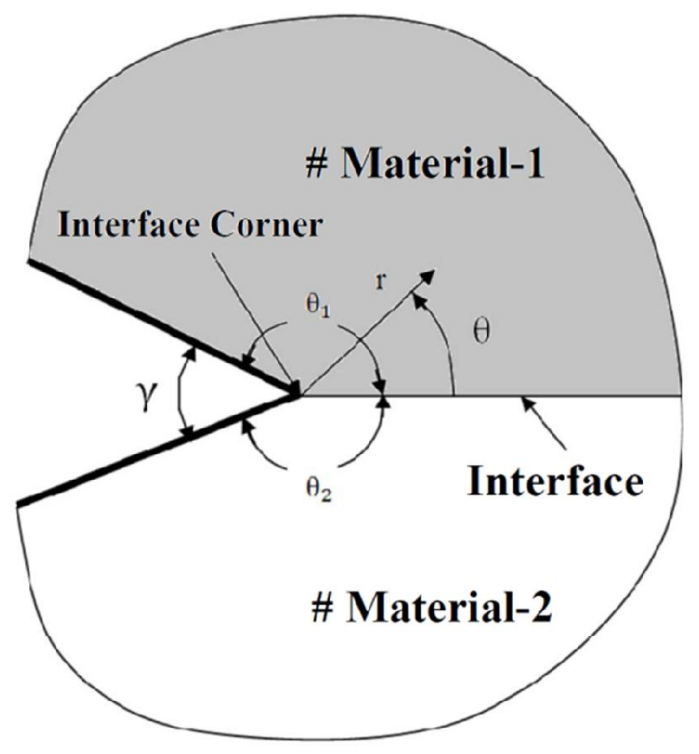

Fig. 1. General configuration at the interface corner between two dissimilar materials

\section{Photoelastic evaluation of SIFs}

An Al/Polycarbonate bi-material Brazilian disc with a $90^{\circ}$ notch $\left(\theta_{1}=\theta_{2}=135^{\circ}\right)$ was employed to evaluate the SIFs by photoelasticity (see Fig. 2). 


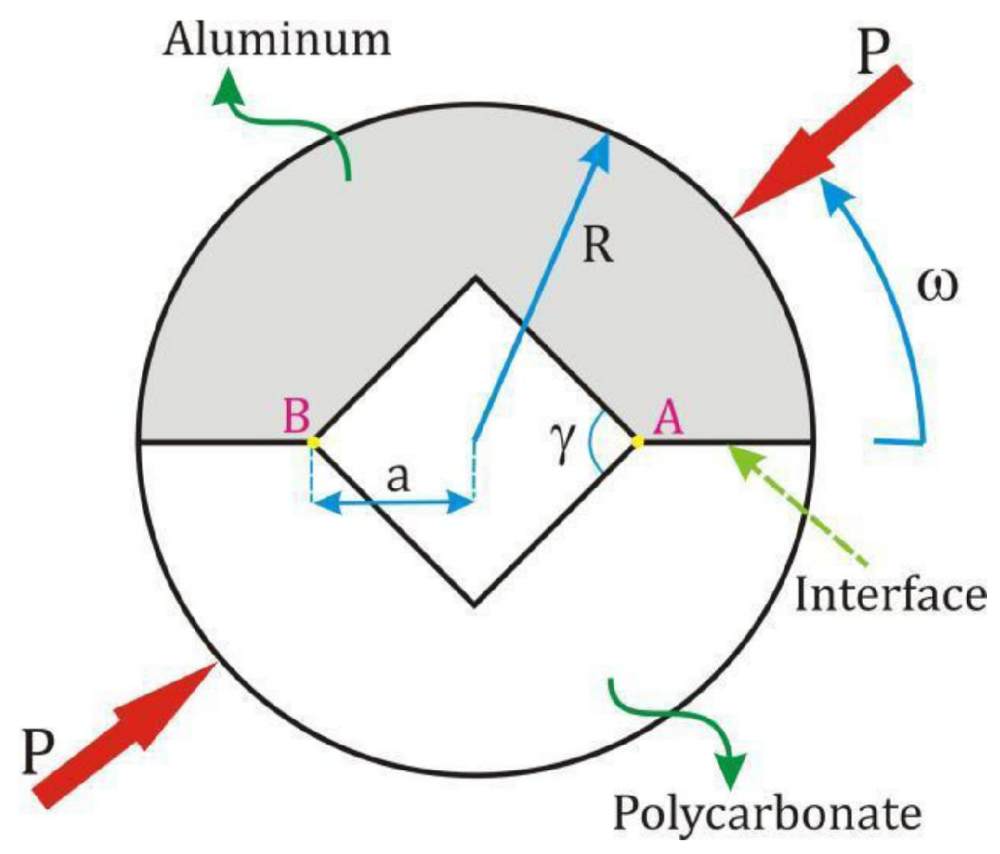

Fig. 2. Bi-material Brazilian disc with a $90^{\circ}$ notch

In order to find the appropriate loading angle of $\omega$ for imposing dominated mode I or mode II on the interface notch, some finite element analyses were performed. In this approach, the SIFs have been calculated by means of overdeterministic method. In order to utilize the advantages of whole-field photoelasticity and minimize the experimental errors, a large number of data points have been substituted in the multi-parameter stress field equations. Then the resulting system of nonlinear equations has been solved employing the over-deterministic least squares method coupled with Newton-Raphson algorithm (details can be found in Ayatollahi et al., 2010). The results of mode I and mode II SIFs against loading angle $\omega$ are shown in Fig. 3. According to this graph, mode I and mode II conditions are obtained for $\omega=90^{\circ}$ and $\omega=72^{\circ}$, respectively.

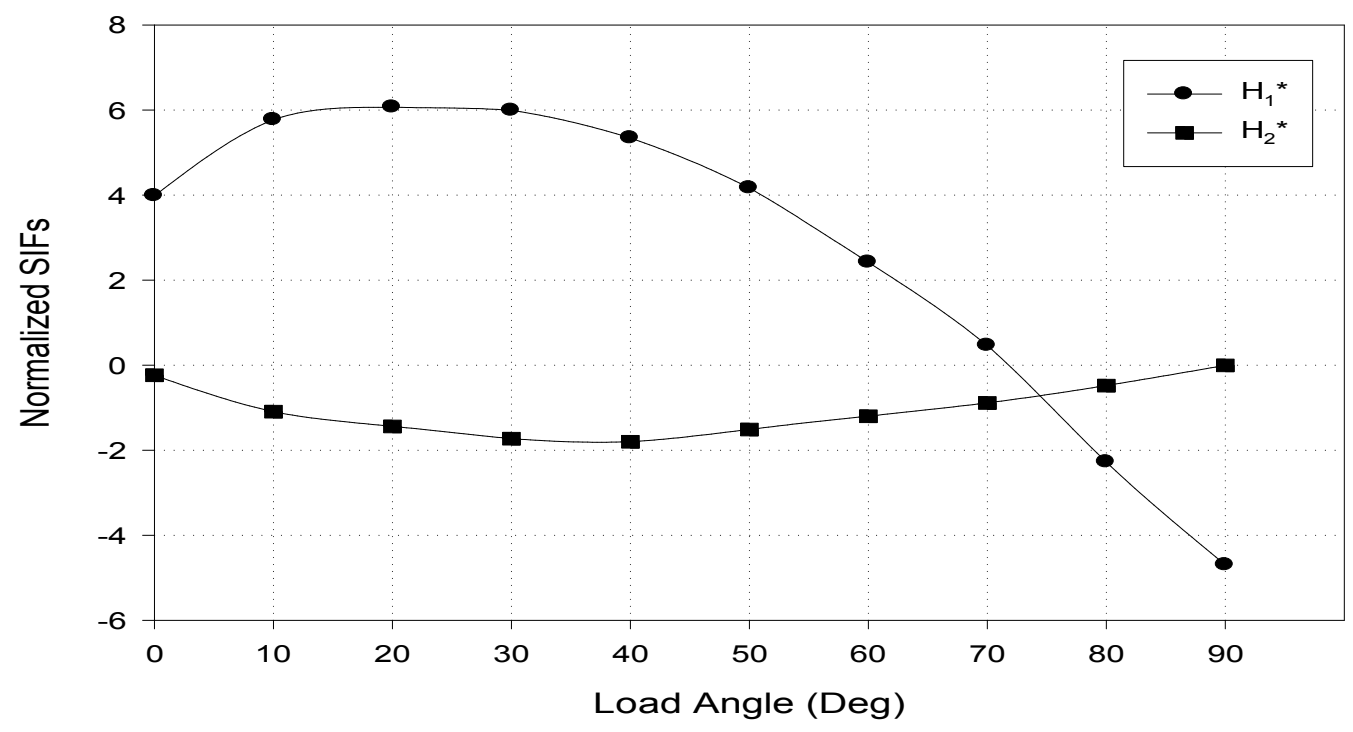

Fig. 3. Variation of SIFs against loading angle $\omega$ 
Hence, photoelastic experiments have been conducted for these loading angles where modes I and II are dominant. Fig. 4 shows the photoelastic fringe patterns for the two mentioned conditions. A large number of data points were used near the interface corner at several fringe orders to obtain SIFs from an overdeterministic approach. The experimental and numerical results which have been normalized by employing Eq. (2) are presented in Table 1. To verify the experimental results, several finite element (FE) analyses were also performed and the notch parameters were calculated numerically. The V notch biomaterial Brazilian disc (VBBD) specimen with the notch angle $\gamma=90^{\circ}$ was modeled and analyzed under the same loading and geometry conditions as the experiments. The six-node quadratic triangular elements were used for the first row of the elements surrounding the notch tip and the eight-node quadratic quadrilateral elements were also utilized for the rest of the model. It is seen from Table 1 that the experimental and numerical results are in a good agreement.

$\mathrm{H}_{1}^{*}=\frac{\mathrm{H}_{1} \mathrm{R}^{\lambda_{1}} \mathrm{~h}}{\mathrm{P}}, \quad \mathrm{H}_{2}^{*}=\frac{\mathrm{H}_{2} \mathrm{R}^{\lambda_{2}} \mathrm{~h}}{\mathrm{P}}$

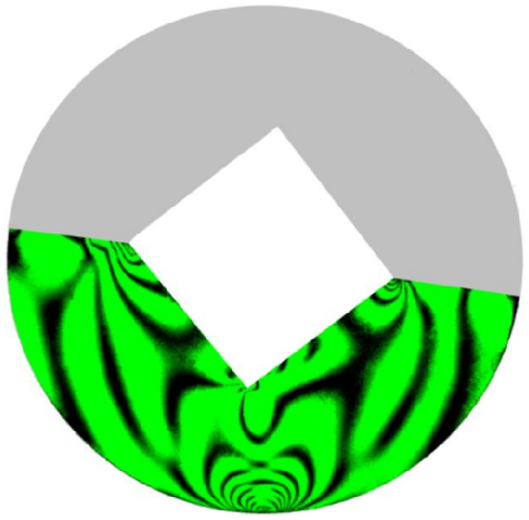

(a)

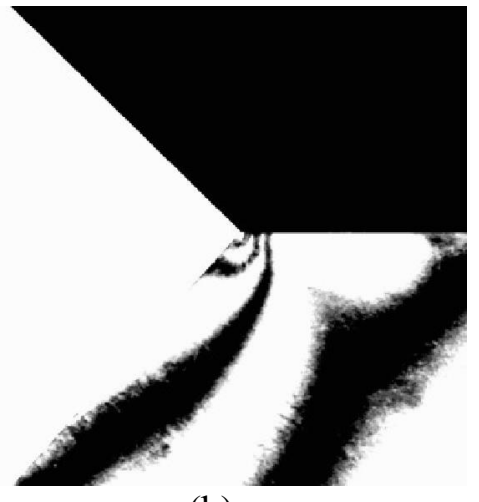

(b)

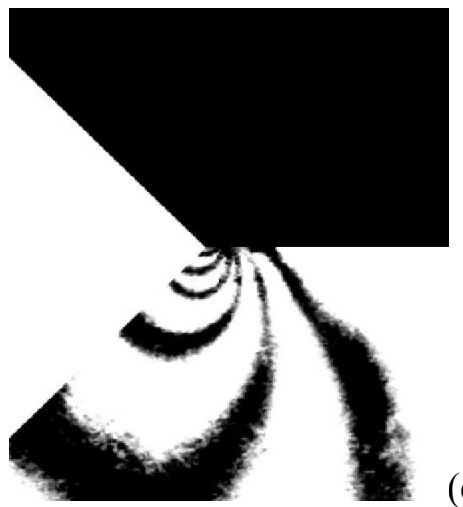

(c)

Fig. 4. (a). colored isochromatic fringe pattern $\theta^{\prime}=72^{\circ}$, (b) monochromatic isochromatic fringe pattern $\omega^{\prime}=72^{\circ}$

and (c) monochromatic isochromatic fringe pattern $\omega^{\prime}=90^{\circ}$

Table 1. Normalized mode I and mode II SIF values for two loading angles of $\omega^{\prime}=72^{\circ}$ and $\omega^{\prime}=90^{\circ}$ obtained from photoelasticity and FE results

\begin{tabular}{cccccc}
\hline Mode $\mathrm{I}\left(\omega^{\prime}=72^{0}\right)$ & photoelasticity & FE results & Mode II $\left(\omega^{\prime}=90^{\circ}\right)$ & Photoelasticity & FE results \\
\hline $\mathrm{H}_{1}^{*}$ & 0.0012 & 0 & $\mathrm{H}_{1}^{*}$ & -4.17 & -4.698 \\
$\mathrm{H}_{2}^{*}$ & -0.763 & -0.825 & $\mathrm{H}_{2}^{*}$ & -0.00587 & -0.00648 \\
\hline
\end{tabular}

\section{Conclusion}

The stress field parameters in the neighborhood of an interface notch were evaluated by the photoelasticity technique. Stress intensity factors for a bi-material notch specimen called V-notched bi-material Brazilian disc (VBBD) specimen were calculated using both numerical and experimental method of photoelasticity. It was shown that The VBBD with AL/ Polycarbonate interface is capable to create both pure mode I and pure mode II conditions. Experimental results of photoelasticity were in good agreement with the numerical values of FE analyses. 


\section{References}

Aliha, M. R. M., \& Ayatollahi, M. R. (2009). Brittle fracture evaluation of a fine grain cement mortar in combined tensile-shear deformation. Fatigue \& Fracture of Engineering Materials \& Structures, 32(12), 987-994.

Aliha, M. R. M., Ayatollahi, M. R., \& Akbardoost, J. (2012). Typical Upper Bound-Lower Bound Mixed Mode Fracture Resistance Envelopes for Rock Material. Rock mechanics and rock engineering, 45(1), 65-74.

Aliha, M. R. M. (2013). Indirect tensile test assessments for rock materials using 3-D disc-type specimens. Arabian Journal of Geosciences, 1-10.

Ayatollahi, M. R., Mirsayar, M. M., \& Dehghany, M. (2011). Experimental determination of stress field parameters in bi-material notches using photoelasticity. Materials \& Design, 32 (10), 49014908.

Ayatollahi, M. R., \& Aliha, M. R. M. (2008). On the use of Brazilian disc specimen for calculating mixed mode I-II fracture toughness of rock materials. Engineering Fracture Mechanics, 75(16), 4631-4641.

Ayatollahi, M. R., Mirsayar, M. M., \& Nejati, M. (2010). Evaluation of first non-singular stress term in bi-material notches. Computational Material Science, 50, 752-760.

Ayatollahi, M. R., Dehghany, M., \&Mirsayar, M. M. (2013). A comprehensive photoelastic study for mode I sharp V-notches.European Journal of Mechanics-A/Solids, 37, 216-230.

Chang, S. H., Lee, C. I., \& Jeon, S. (2002). Measurement of rock fracture toughness under modes I and II and mixed-mode conditions by using disc-type specimens. Engineering geology, 66(1), 7997.

Mirsayar, M. M.,\& Samaei, A.(2013). Photoelastic study of bi-material notches: Effect of mismatch parameters. Engineering Solid Mechanics 1 (1), 21-26.

Ravichandran, M.,\& Ramesh, K.(2004). Determination of Stress Intensity Factors for an Interfacial Crack in a Bi-material by Digital Photoelasticity. Applied Mechanics and Materials, 1-2, 139-146.

Ravichandran, M., \&Ramesh, K. (2005). Evaluation of stress field parameters for an interface crack in a bimaterial by digital photoelasticity. Journal of Strain Analysis, 40, 327-343.

Torabi, A. R., \& Taherkhani, M. (2011). Extensive data of notch shape factors for V-notched Brazilian disc specimen under mixed mode loading. Materials Science and Engineering: A, 528(29), 8599-8609.

Torabi, A. R., \& Jafarinezhad, M. R. (2012). Comprehensive data for rapid calculation of notch stress intensity factors in U-notched Brazilian disc specimen under tensile-shear loading. Materials Science and Engineering: A, 541, 135-142. 